\title{
Sub Periosteal and Intra Ethmoidal Displacement of Gutta Percha Cone Following Endodontic Intervention of Maxillary First Molar
}

\author{
Desplazamiento Subperióstico e Intraetmoidal del Cono de Gutapercha \\ después de la Intervención Endodóntica del Primer Molar Superior
}

\author{
Nyer Firdoose ${ }^{1} \&$ Mohamad Awadalla ${ }^{2}$
}

FIRDOOSE, N. \& AWADALLA, M. Sub periosteal and Intra ethmoidal displacement of gutta percha cone following endodontic intervention of maxillary first molar. Int. J. Odontostomat., 15(3):574-576, 2021.

ABSTRACT: Foreign bodies in the ethmoid sinus are uncommon, and endodontic gutta percha displacement is even more rare. We present and discuss a case of displacement of gutta percha into the ethmoid sinus following root canal intervention of a maxillary first molar which presumably migrated through the maxillary sinus. There have been reports on the displacement of tooth roots or implants into the maxillary sinus. However, we know of only one such report on the migration of a gutta-percha point into the ethmoid sinus.

KEY WORDS: gutta percha, ethmoidal sinus, displacement.

\section{INTRODUCTION}

Endodontic intervention is one of the most common outpatient dental procedures which rarely involves serious complications. However, accidents do occur leading to displacement of either root canal fillers or sealers or even gutta percha, and the most common areas of displacement include the maxillary sinuses and sub periosteal tissues (Kılınc et al., 2016). Although, there are reports of displaced foreign bodies in ethmoid sinus (Elango \& Htun, 1993; MassaroGiordano et al., 1998; Haben et al., 2003), to the best of our knowledge, there is only one previously reported case of gutta percha migration into the ethmoidal sinus (Ishikawa et al., 2004). We aim to present and discuss the aetiology and management of such a rare event.

\section{CASE REPORT}

A 31-year-old Saudi female was referred to the maxillofacial clinic with symptoms of maxillary sin- usitis including tenderness in the right infraorbital region and nasal congestion. The patient gave history of multiple root canal interventions on her maxillary right first molar for over a year. Although the final restoration of the crown had been completed, she developed tenderness in the right infraorbital region six months later with intra oral sinus drainage over the buccal aspect of the same tooth for which the general dentist did gutta percha tracing of the sinus tract. The root canal was treated again, but the symptoms did not subside. Her final panoramic radiograph revealed extrusion of root canal filling material from all three roots and the probable intrusion of gutta percha into the sinus floor over the mesial root, the tooth was deemed non-restorable. Incidentally, a slender radio opaque object was noted over the medial wall of the right orbit (Fig. 1). Minimally traumatic extraction of maxillary right first molar was done followed by Cone beam computed tomography (CBCT) acquisition to evaluate and confirm the panoramic findings.

\footnotetext{
${ }^{1}$ Associate consultant, Oral \& Maxillofacial surgery, Riyadh Specialized Dental Center, Riyadh, Ishbiliyah, KSA.

${ }^{2}$ Consultant Implantologist, Riyadh Specialized Dental Center, Riyadh, Ishbiliyah, KSA.
} 


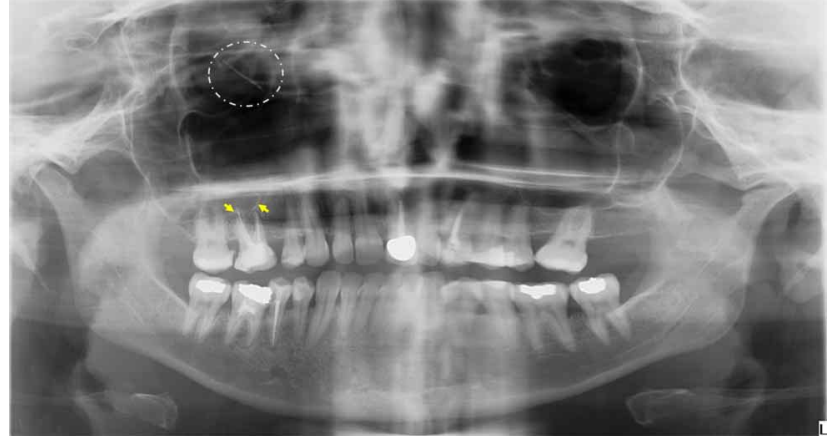

Fig. 1 Panoramic radiograph shows extruded root canal filing material over the roots of maxillary right first molar (yellow arrows) in proximity to the sinus floor and a slender foreign body over the medial wall of right orbit (dotted circle)

On CBCT evaluation, a perforation over the lateral wall of maxillary sinus and a sub periosteal gutta percha with its tip curved over the buccal aspect of socket of first molar (Fig. 2a) and slender foreign body in the region of the right ethmoidal sinus were confirmed. The foreign body was located in the osteomeatal complex starting at the maxillary osteum antero inferiorly running along the ethmoid infundibulum and extending superiorly up to the posterior ethmoid sinus with the tip being stopped by the ethmoidal roof or fovia ethmoidalis, finally resting along the lamina papyracea medial to the right orbital wall (Fig. 2b). The patient complained of pressure over the back of the right eye with no changes in her vision. She also gave history of repeated bouts of sinusitis for which she was under symptomatic management. She was not

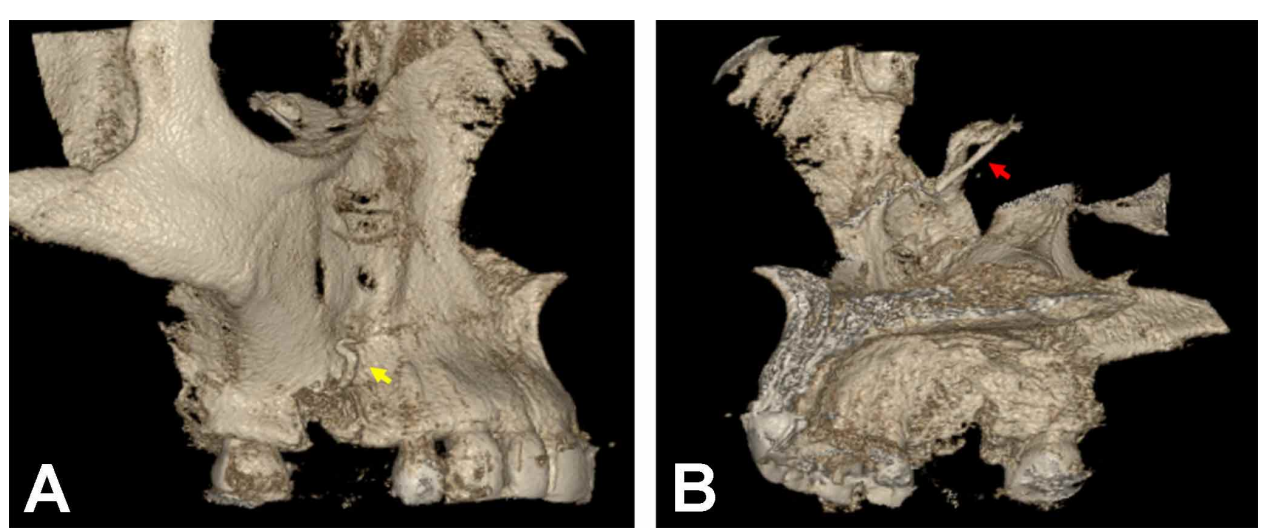

Fig. 2. Three-dimensional reconstruction of CBCT scans. A Showing bent foreign body lateral to socket of extracted maxillary first molar (yellow arrow). B. Showing a slender foreign body medial to the orbital wall (red arrow).
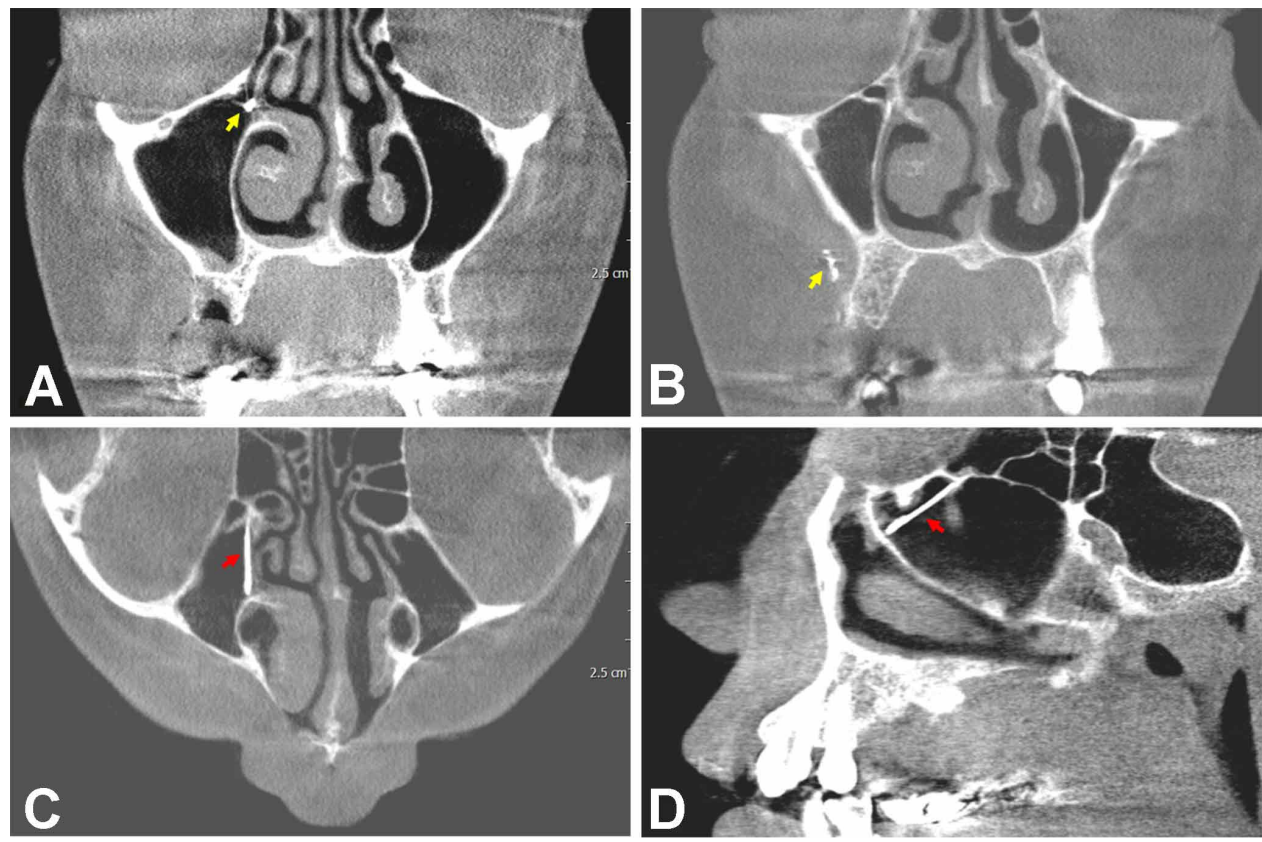

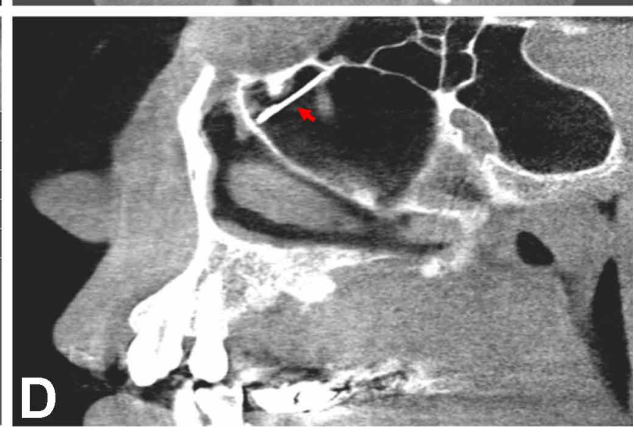

informed about the presence of the foreign body or the displaced gutta percha sub periosteally (Fig. 3). The foreign body from the ethmoid sinus was removed under local anaesthesia using an endoscope through a lateral antrostomy along with the subperiosteal gutta percha from buccal aspect of the extracted first molar socket. The foreign body was confirmed as a guttapercha point $18 \mathrm{~mm}$ long (Fig. 4). The postoperative course was uneventful and satisfactory with no repeated sinus infection.

Fig. 3. CBCT scan images. A. Coronal view showing foreign body at the maxillary osteum (yellow arrow). B. Coronal view showing sub periosteal foreign body lateral to right maxillary cortical plate (yellow arrow). C. Axial view showing a slender foreign body extending from anterior ethmoidal sinus to posterior ethmoidal sinus (red arrow). D. Sagittal view showing thw foreign body directed upwards with the tip at the ethmoidal roof. Medial to the orbital wall (red arrow). 


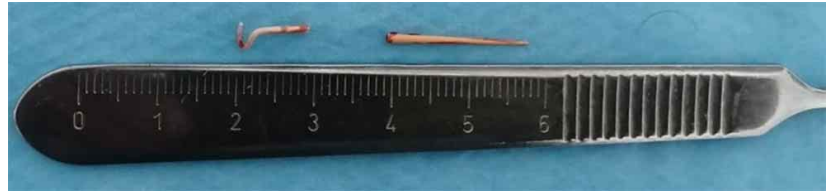

Fig. 4 Retrieved gutta percha from sub periosteal tissue and from the ethmoid sinus.

\section{DISCUSSION AND CONCLUSION}

The most commonly found foreign bodies are displaced fractured roots of teeth and in some instances, whole displaced teeth. Other foreign bodies include dental burs and implants. In literature there are very few reported cases of foreign bodies in the ethmoid sinus of which only one is about a migrated gutta percha cone through the maxillary sinus, the others include a ball point pen, floor implant, an air gun pellet, and a nail or wooden foreign body. While most of them were related to the orbital floor (Murthy et al., 1994; Yamaguchi et al., 2007; Kılınc et al.), As per our knowledge this report is only a second case of gutta percha displacement into the ethmoid sinus along with a sub periosteal displacement of gutta percha during the buccal sinus tract tracing that we are aware.

However the route of the displaced gutta percha cone was not clear, migration through the lateral wall perforation of the right maxillary sinus seemed plausible, because the initial radiograph from the referral clinic, showed a projection of gutta-percha points from the roots into the maxillary sinus. As there is no direct anatomical communication between the ethmoid and maxillary sinus, it is most likely that the gutta-percha point got displaced from the maxillary sinus into the nasal cavity through the osteomeatal complex, and then resting into the ethmoid sinus during the course of its displacement. It is therefore important to have an accountability of intra canal obturation materials along with judicious use of force during tracing of sinus tract and canal obturation to avoid displacement of gutta percha into adjacent tissue spaces.

FIRDOOSE, N. \& AWADALLA, M. Desplazamiento subperióstico e intraetmoidal del cono de gutapercha después de la intervención endodóntica del primer molar superior. Int. J. Odontostomat., 15(3):574-576, 2021.

RESUMEN: Los cuerpos extraños en el seno etmoidal son infrecuentes y el desplazamiento de la gutapercha endodóntica es aún más raro. Presentamos y analizamos un caso de desplazamiento de la gutapercha hacia el seno etmoidal después de la intervención del conducto radicular de un primer molar superior que se presume migró a través del seno maxilar. A pesar de que existen informes sobre el desplazamiento de raíces dentales o implantes hacia el seno maxilar, solo conocemos un informe de este tipo sobre la migración de un punto de gutapercha hacia el seno etmoidal.

PALABRAS CLAVE: gutapercha, seno etmoidal, desplazamiento.

\section{REFERENCES}

Elango, S. \& Htun, Y. N. Nail in the ethmoidal sinus: an unusual entry. J. Otolaryngol., 22(3):206, 1993.

Haben, C. M.; Balys, R. \& Frenkiel, S. Dental implant migration into the ethmoid sinus. J. Otolaryngol., 32(5):342-4, 2003.

Ishikawa, M.; Mizuno, T.; Yamazaki, Y.; Satoh, T.; Notani, K. \& Fukuda, $\mathrm{H}$. Migration of gutta-percha point from a root canal into the ethmoid sinus. Br. J. Oral Maxillofac. Surg., 42(1):58-60, 2004.

Kılınc, A.; Sancar, B.; Saruhan, N. \& Ertas, U. Accidental displacement of gutta-percha to the lingual periosteum: a case report. Turk. Endod. J., 1(2):87-90, 2016.

Massaro-Giordano, M.; Kirschner, R. A. \& Wulc, A. E. Orbital floor implant migration across the ethmoidal sinuses and nasal septum. Am. J. Ophthalmol., 126(6):848-50, 1998.

Murthy, P. S.; Sahota, J. S.; Nayak, D. R.; Balakrishnan, R. \& Hazarika, P. Foreign body in the ethmoid sinus. Int. J. Oral Maxillofac. Surg., 23(2):74-5, 1994.

Yamaguchi, K.; Matsunaga, T. \& Hayashi, Y. Gross extrusion of endodontic obturation materials into the maxillary sinus: a case report. Oral Surg. Oral Med. Oral Pathol. Oral Radiol. Endod., 104(1):131-4, 2007.

Corresponding author:

Dr. Nyer Firdoose

Oral \& Maxillofacial surgery

Riyadh Specialized Dental Center

Riyadh, Ishbiliyah

KSA

E-mail: drnyeromfs@gmail.com 